\title{
SLIDING MODE CONTROL OF THE DFIG USED IN WIND ENERGY SYSTEM
}

\begin{abstract}
This paper, presents the application of the direct vector control using the sliding mode control (SMC) on the doubly fed induction generators (DFIG). The synthesis of the control laws is based on the model obtained by the orientation of the stator flux. The active and reactive powers that are generated by the doubly fed induction generators will be decoupled by the orientation of the stator flux and controlled by sliding mode controllers that have been developed. In order to rule on the validity as well as the performance of this type of adjustment, we will check its robustness by varying some parameters of the machine doubly fed induction. References 34, figures 9.
\end{abstract}

Key words: doubly fed induction generators (DFIG), vector control, sliding mode control.

Цель. В статье представлено применение прямого векторного управления с использованием управления режимом скольжения (SMC) на индукционных генераторах двойного питания (DFIG). Синтез законов управления основан на модели, полученной с помоцью ориентации потока статора. Активные и реактивные моцности, генерируемые индукциоными генераторами двойного питания, разделены ориентацией потока статора и управляются разработанными контроллерами режима скольжения. Чтобы определить достоверность и эффективность данного типа регулирования, проверяется его надежнноть путем варьирования ряда параметров машины двойного питания. Библ. 34, рис. 9.

Ключевые слова: индукционные генераторы двойного питания (DFIG), векторное управление, управление режимом скольжения.

Introduction. The technique of sliding mode control (SMC) was first developed for a linear system of the second order, and since then, the spectrum of its use has been extended to a larger case of linear, nonlinear, discrete and multi-variable systems $[1,2]$. Variable structure control has gained some popularity because of its simplicity and efficiency. In such a system, the command by switching makes it possible to bring the figurative point of the evolution of the system on the super sliding surface. When this hyper-surface is reached, the sliding regime occurs [3-5].

Many strategies have been developed over the past decade to optimize the power extracted from the wind energy conversion system. Several authors have tackled the control problem of electrical machines operating in the fieldweakening region. For example, Taraft and all [6], Saleh Mobayen, Fairouz Tchier [7], Ansarifar, and all [8], Bartolini and al. [9], Benbouzid and al. [10], Seibel and al. [11] which used the sliding mode approach to achieve active and reactive power control. Hongchang Sun and all [12] explored the maximum wind power tracking of doubly fed wind turbine system based on adaptive gain second-order sliding mode. Kassem and all [13], Belmokhtar and all [14] proposed a dynamic modeling and robust power control of doubly fed induction generators (DFIG) driven by wind turbine at infinite grid. Weng and al. [15] a sliding mode regulator for maximum power tracking and copper loss minimisation of a doubly fed induction generator. Abdeddaim and all [16] Optimal tracking and robust power control of the DFIG wind turbine.

With the planned strategy, the generated wind energy can reach twice its nominal value thanks to a fast and reliable electric control completely robust. Indeed, by employing an appropriate control technique where the power produced in DFIG mode is derived from both the stator and the rotor. In addition, the power supplied by the rotor increases in this case by $100 \%$ with respect to the nominal power of the stator. However, this solution makes it possible to maintain the operation of the wind energy conversion system in its stable zone.

The system considered consists of a dual-feed induction generator whose stator is directly connected to the gate and its rotor is powered by a matrix converter. In this paper, the sliding-mode approach to performing active and reactive power control is used.

This last enjoys interesting strong properties such as the insensitivity to the variations of the parameters of the controlled part as well as to the disturbances, which can act on this last one. Its behavior does not depend any more than the parameters that define the hyperactive surface of the slip. Despite having various advantages, this control technique also has a disadvantage that limited its use initially. Indeed, in practice, imperfections such as switching delays and hysteresis generate oscillations around the sliding surface. Several techniques have been proposed to overcome this disadvantage $[11,17]$. Some consist in approximating the discontinuous function by a continuous function in the vicinity of the switching surface, the reduction of chattering taking place at the cost of a loss of precision. Due to the many advantages of variable structure control, such as robustness, speed, and simplicity of implementation, this type of control seems to us quite suitable for dual feed generators for which performance can be required. Moreover, as some parameters of the generator prove to vary during the operation and that the load is often unknown; the control will have to take into account these parametric disturbances and variations to avoid a degradation of performances [18]. The main objective of this paper is to advance the understanding of the controlled SMC in the wind system, by studying its behavior with wind energy system. Taking into account many unresolved issues associated with wind energy, the results of the analysis and evaluation of discretization behaviors in the SMC systems are essential for their applications in the control of renewable energies [19].

However, the analysis and evaluation of discretization behaviors in SMC systems has proved to be a difficult task due to the lack of work done on this topic. There is apparently a gap between the expected ideal dynamic performance based on continuous-time system models and the actual dynamic performance when the

(C) H. Glaoui, A. Harrouz 
control system is discretized. Delay in delivery of control signals due to discretization is the key factor affecting control performance. This is especially true when the control is of a discontinuous nature, such as SMC. «Disruptive» switching may cause incorrect actions due to the timely delivery of control signals. These behaviors can cause serious damage to industrial control devices such as actuators [19]. In addition, the deteriorated invariance property can worsen the reliability of SMC systems, making controlled industrial processes vulnerable to unexpected environmental changes.

Issues of interest in studying discretization behaviors in SCM systems include:

- conditions to ensure stability;

- steady state boundary conditions;

- system trajectory models (periodicity);

- sensitivity of trajectories to initial conditions;

- relationship between trajectory models and their symbolic sequences;

- dynamic behavior change with respect to the sampling period.

To our knowledge, this research is the first to systematically study the discretization behaviors of SMC systems, and to develop methods for controlling the wind system based on the DFIG generator. The significance of this work lies in the fact that it promotes the understanding of discretization behaviors in SMC systems, thus providing useful measures to prevent potential behavior from occurring. It also results in new methods useful not only for the analysis of the discretization of the SMC systems, but also for the synthesis of the laws of the controls as a function of the model obtained by the orientation of the stator flux.

The characteristic feature of a continuous time SMC systems is that a sliding mode occurs on a prescribed manifold, or switching surface, where a switching control is employed to maintain the state on that surface [20-23]. Since the theory has been originally developed from a continuous time perspective, implementation of sliding mode for sampled data systems encounters several incompatibilities due to limited sampling rate, sample/hold effect, and discretization errors. As a result, a direct translation of continuous-time SMC design for discrete implementation leads to the chattering phenomenon in the vicinity of the switching surface.

In this paper, basic results obtained in the study of continuous-time and discrete-time SMC systems theory during its over twenty years history are reviewed. The discretization issue of SMC systems is introduced.

Machine model. Flux-Oriented Vector Control presents an attractive solution for achieving better performance in variable speed applications for the doubly fed induction machine in both generator and motor operation. With this in mind, we have proposed a control law for the DFIM (doubly fed induction machine) based on the orientation of the stator flux, used to make it work as a generator. The latter highlights the relationships between the stator and rotor quantities [24-26]. These relationships will allow to act on the rotor signals to control the active power exchange and reactivate between the stator of the machine and the power system.
The wind turbine rotates at a speed that depends on the wind speed (Fig. 1). This speed is matched to that of the electric generator through a gearbox $[27,28]$.

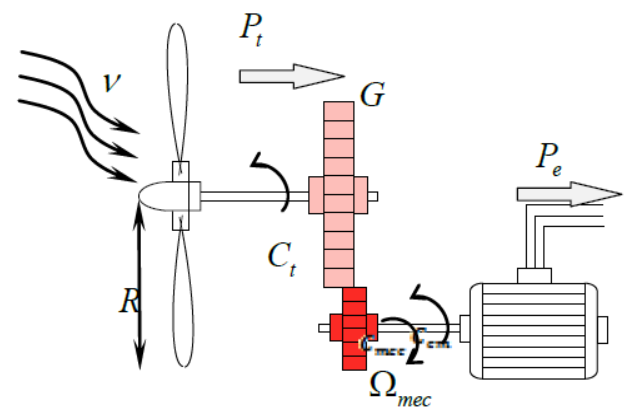

Fig. 1. Wind turbine model

The output power of wind turbine is given as

$$
p_{m}=\frac{\rho A}{2} C_{p}(\lambda, \beta) v_{\text {wind }}^{3},
$$

where, $p_{m}$ is mechanical output power of the turbine (W); $\rho$ is air destiny $\left(\mathrm{kg} / \mathrm{m}^{3}\right) ; A$ is turbine swept area $\left(\mathrm{m}^{2}\right) ; \beta$ is blade pitch angle (deg); $\lambda$ is tip speed ratio of the rotor blade tip speed to wind speed; $C_{p}$ is performance coefficient of wind turbine, which is the function of $\beta$ and $\lambda ; v_{\text {wind }}$ is wind speed $(\mathrm{m} / \mathrm{s})$.

The tip speed ratio $\lambda$ is calculated as

$$
\lambda=\frac{R \omega_{T}}{v_{\text {wind }}} .
$$

From an engineering point of view, there are many different representing methods of performance coefficient $C_{p}$.

But they all represent $C_{p}$ as a nonlinear function of $\beta$ and $\lambda$. In this paper, $C_{p}$ is denoted as

$$
\left.C_{p}(\lambda, \beta)\right)=C_{1}\left(\left(\frac{C_{2}}{\lambda_{i}}-C_{3}(\beta+2.5)-C_{4}\right) e^{\frac{-C_{5}}{\lambda_{i}}}+C_{6} \lambda_{i},\right.
$$

where $C_{1}=0.645, C_{2}=116, C_{3}=0.4, C_{4}=5, C_{5}=21$, $C_{6}=0.00912$.

Variable $\lambda_{i}$ can be calculated as

$$
\frac{1}{\lambda_{i}}=\frac{1}{\lambda+0.08(\beta+2.5)}-\frac{0.035}{(\beta+2.5)^{3}+1} .
$$

Wind turbine dynamics simulations have been run for wind step changes. The characteristic feature of the dependence of the wind turbine power upon the wind speed has been illustrated in Fig. 2 (the nominal power being $2 \mathrm{MW}$ ) [29].

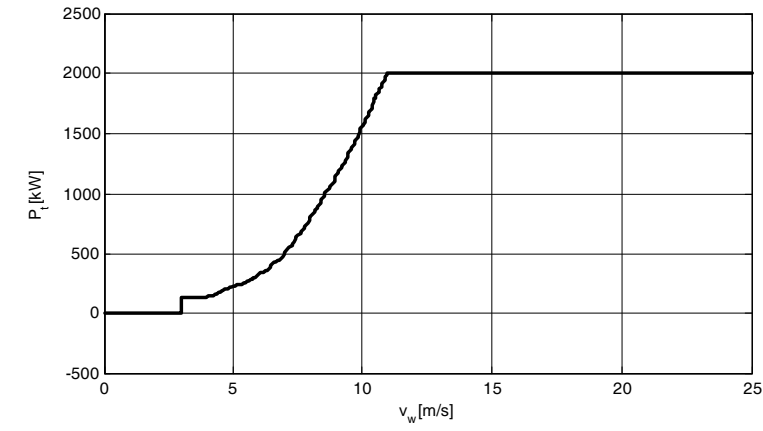

Fig. 2. Static characteristic of wind turbine mechanical power as a function of mean wind speed

For a given wind speed $v_{m}$ the wind turbine power $p_{t}$ and the moment $m_{t}=p_{t} / w_{t}$. 
Model of generator «DFIG». In order to implement the decoupling control of active and reactive power, it is essential to transform the voltage and current of induction generator stator and rotor from 3-phase form to $d q$ form under synchronous rotation coordinates. In addition, the voltage and flux equations of induction generator are seen as (5) and (6) respectively

$$
\begin{aligned}
& V_{d s}=R_{s} I_{d s}+\frac{d}{d t} \psi_{d s}-\dot{\theta}_{s} \psi_{q s} ; \\
& V_{q s}=R_{s} I_{q s}+\frac{d}{d t} \psi_{q s}-\dot{\theta_{s}} \psi_{d s} ; \\
& V_{d r}=R_{r} I_{d r}+\frac{d}{d t} \psi_{d r}-\dot{\theta}_{r} \psi_{q r} ; \\
& V_{q r}=R_{r} I_{q r}+\frac{d}{d t} \psi_{q r}-\dot{\theta}_{r} \psi_{d r} ; \\
& \psi_{d s}=L_{r} I_{d s}+M I_{d r} ; \\
& \psi_{q s}=L_{s} I_{q s}+M I_{q r} ; \\
& \psi_{d r}=L_{r} I_{d r}+M I_{d s} ; \\
& \psi_{q r}=L_{r} I_{q r}+M I_{q s},
\end{aligned}
$$

where $V_{d s}, V_{q s}, V_{d r}$ and $V_{q r}$ are respectively the $d q$ coordinates components of stator and rotor voltage; $I_{d s}$, $I_{q s}, I_{d r}$ and $I_{q r}$ are respectively the $d q$ coordinates components of stator and rotor current; $\psi_{d s}, \psi_{q s}, \psi_{d r}$ and $\psi_{q r}$ are respectively the $d q$ coordinates components of stator and rotor flux; $L_{r}, L_{s}$ and $M=L_{m}$.

The electromagnetic torque is expressed as:

$$
\begin{gathered}
C_{e m}=3 / 2\left(\psi_{d s} I_{q s}-\psi_{q s} I_{d s}\right) ; \\
P=V_{d s} I_{d s}-V_{q s} I_{q s} ; \\
Q=V_{q s} I_{d s}-V_{d s} I_{q s} .
\end{gathered}
$$

This strategy consists to turn the rotor flux towards $d$ axis, and the stator flux towards $q$ axis. After orientation the stator and rotor fluxes are presented in Fig. 3

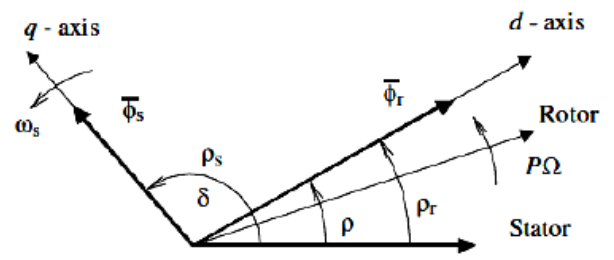

Fig. 3. DFIG vector after orientation

Consequently, the two fluxes become orthogonal and we can write:

$$
\psi_{q s}=\psi_{s} ; \quad \psi_{d r}=\psi_{r} ; \quad \psi_{q r}=\psi_{d s}=0
$$

If resistance $R_{s}$ is neglected we have:

$$
V_{q s}=\frac{d}{d t} \psi_{q s}=0 ; \quad V_{d s}=V_{s} .
$$

The developed active power and reactive power can be rewritten as follows:

$$
P=V_{s} I_{d s} ; \quad Q=-V_{s} I_{q s},
$$

where

where

$$
I_{d s}=-\frac{M}{L_{s}} I_{d r} ; \quad I_{q s}=-\frac{L_{r}}{M} I_{q r}
$$

$$
P=-V_{s} \frac{M}{L_{s}} I_{d r} ; \quad Q=V_{s} \frac{L_{r}}{M} I_{q r} .
$$

Sliding Mode Control. The term «variable structure systems» appears because of the particular structure of the system or regulator used, where this structural change in a discontinuous manner between two or more structures.

In the formulation of any practical control problem, there will always be a discrepancy between the actual plant and its mathematical model used for the controller design. These discrepancies (or mismatches) arise from unknown external disturbances, plant parameters, and parasitic/modeled dynamics [30, 31]. Designing control laws that provide the desired performance to the closed-loop system in the presence of these disturbances/uncertainties is a very challenging task for a control engineer. This has led to intense interest in the development of the so-called robust control methods, which are supposed to solve this problem. One particular approach to robust controller design is the socalled sliding mode control technique.

The behavior of nonlinear systems with discontinuities can be formally described by the generalized state equation:

$$
\dot{X}(t)=F(X, t, U)
$$

where $X \in \mathfrak{R}^{n}$ is the state vector, $t$ time and is the function describing the evolution of the system over time. This class of system has a term which represents, at the same time, the discontinuity and the control: $U$.

Historically, the first regulators built on this model have been simple relays. Easy to implement. They have led the automation engineers to develop a theory that can describe such an operation. The bases of such a theory have been laid: it suffices to say that the behavior of the system is described by two distinct differential equations, depending on whether the equation of evolution of the system is greater or less than a surface called hypersurface (increased surface) switching where:

So we have

$$
S(X)=\left(S_{1}(X), S_{2}(X), \ldots ., S_{m}(X)\right) .
$$

$$
U(X)= \begin{cases}U^{+}(X, t), & \text { if } \quad S(X, t)>0 \\ U^{-}(X, t), & \text { if } \quad S(X, t)<0 .\end{cases}
$$

We consider a nonlinear system defined as

$$
x^{(n)}(t)=f(x, t)+b(x, t) u(x, t)
$$

where $x$ is the state vector and are nonlinear functions and is the control input $f(x, t), b(x, t) u$.

To design a sliding mode control law, we must firstly, choose the switching surface (Fig. 4).

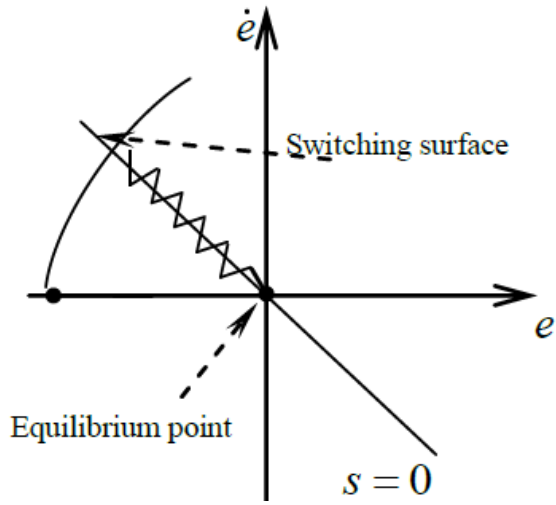

Fig. 4. Sliding mode in a phase plane 
We take the general form proposed by Slotine [24]:

$$
S=\left(\frac{d}{d t}+\lambda\right)^{(n-1)} e,
$$

where $e=x-x_{d}$ is the tracking error; is $x_{d}$ the desired state, is $n$ the system order and $\lambda$ is a positive coefficient.

After choosing the sliding surface, we must choose the control law where the reaching condition defined by Lyapunov equation satisfied

$$
S S<0 \quad \forall t .
$$

The control law has the following form.

Thus, the vector control to be applied to the system is obtained by adding two control terms such as

$$
U=U_{e q}+U_{n},
$$

where $U_{e q}$ on the sliding mode; $U_{n}$ allows to influence the approach mode.

In order that the condition (19) is verified at any time, is chosen as follows [32] (a complete study of sliding-mode with ERL can be found in [32]

$$
\dot{S}=-\frac{k}{\delta_{0}+\left(1-\delta_{0}\right) e^{-\alpha|S|^{p}}} \operatorname{sat}\left(\frac{S}{\phi}\right),
$$

where $k$ is the discontinuous gain,

$$
t_{r d}=\delta_{0} \frac{|S(0)|}{k}+\frac{\left(1-\delta_{0}\right)}{k \alpha^{1 / p}},
$$

is the desired reaching time, $\alpha \geq 0,0<\delta_{0}<1$ and $p>0$, sat $\left(\frac{S}{\phi}\right)$ is the saturation function

$$
\operatorname{sat}\left(\frac{S}{\phi}\right)=\left\{\begin{array}{l}
1, \text { if } \frac{S}{\phi}>1 ; \\
\frac{S}{\phi}, \text { if }-1 \leq \frac{S}{\phi} \leq 1 ; \\
-1, \text { if } \frac{S}{\phi}<-1 .
\end{array}\right.
$$

The use of saturation function instead of sign function is justified to avoid chattering phenomenon.

The sliding mode applied to DFIG. We will use this technique to control the rotor currents of DFIG with a strongly coupled model [33, 34] (Fig. 5).

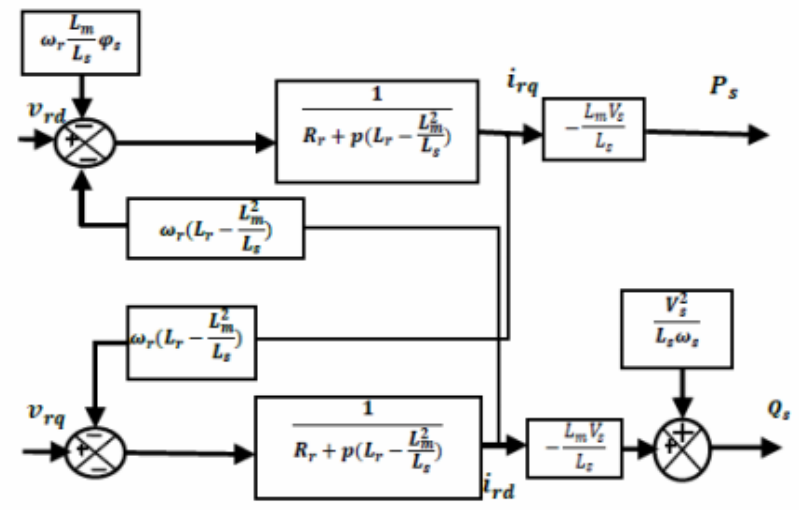

Fig. 5. Global scheme mode of the DFIG control

Recall the model of DFIG in Park's Den which is given by the following equations:

$$
\begin{gathered}
\left\{\begin{array}{l}
V_{d q s}=R_{s} I_{d q s}+\frac{d \Phi_{d q s}}{d t} \mp \omega_{s} \cdot \Phi_{d q s} ; \\
V_{d q r}=R_{s} I_{d q r}+\frac{d \Phi_{d q r}}{d t} \mp \omega_{r} \cdot \Phi_{d q r} ;
\end{array}\right. \\
\left\{\begin{array}{l}
\Phi_{d q s}=L_{s} I_{d q s}+M \cdot I_{d q r} ; \\
\Phi_{d q r}=L_{s} I_{d q r}+M \cdot I_{d q s} .
\end{array}\right.
\end{gathered}
$$

The vector of the state variables chosen for the control of the machine is given by:

$$
x=\left(\begin{array}{c}
\Phi_{d s} \\
\Phi_{q s} \\
I_{d r} \\
I_{q r}
\end{array}\right) .
$$

The model of the machine with the consideration of the state variables is given by the following equations:

$$
\begin{aligned}
& \left(\begin{array}{l}
V_{d s} \\
V_{q s} \\
V_{d r} \\
V_{q r}
\end{array}\right)= \\
& =\left[\begin{array}{l}
R_{s} \cdot a \Phi_{d s}-R_{s} \cdot c\left(L_{r} \sigma I_{d r}+\frac{M}{L_{s} \omega_{s}} V_{q s}\right)-\omega_{s} \Phi_{q s}+\frac{d \Phi_{d s}}{d t} ; \\
R_{s} \cdot a \Phi_{q s}-R_{s} \cdot c\left(L_{r} \sigma I_{q r}+\frac{M}{L_{s} \omega_{s}} V_{d s}\right)+\omega_{s} \Phi_{d s}+\frac{d \Phi_{q s}}{d t} ; \\
R_{r} \cdot b\left(L_{r} \sigma I_{d r}+\frac{M}{L_{s} \omega_{s}} V_{q s}\right)-R_{r} \cdot c \Phi_{d s}-\omega_{r}\left(L_{r} \sigma I_{q r}+\frac{M}{L_{s} \omega_{s}} V_{d s}\right)+L_{r} \sigma \frac{d I_{d r}}{d t} ; \\
R_{r} \cdot b\left(L_{r} \sigma I_{q r}+\frac{M}{L_{s} \omega_{s}} V_{d s}\right)-R_{r} \cdot c \Phi_{q s}+\omega_{r}\left(L_{r} \sigma I_{d r}+\frac{M}{L_{s} \omega_{s}} V_{q s}\right)+L_{r} \sigma \frac{d I_{q r}}{d t} .
\end{array}\right] \\
& a=\frac{1}{\sigma L_{S}}, b=\frac{1}{\sigma L_{r}}, c=\frac{M}{\sigma L_{s} L_{r}} .
\end{aligned}
$$

The state model of the machine is put in the following form:

$$
\begin{gathered}
\dot{X}=f(x, t)+g(x, t) U_{d q} ; \\
\dot{X}=\left[\begin{array}{l}
\frac{d \Phi_{d s}}{d t} \\
\frac{d \Phi_{q s}}{d t} \\
\frac{d I_{d r}}{d t} \\
d I_{q r} \\
d t
\end{array}\right] \cdot g(x, t)=\left[\begin{array}{cccc}
1 & 0 & 0 & 0 \\
0 & 1 & 0 & 0 \\
0 & 0 & \frac{1}{\sigma L_{r}} & 0 \\
0 & 0 & 0 & \frac{1}{\sigma L_{r}}
\end{array}\right] ; \\
{\left[\begin{array}{l}
U_{d q}=\left[V_{d s} V_{q s} V_{d r} V_{q r}\right. \\
-R_{s} \cdot a \Phi_{d s}+R_{s} \cdot c\left(L_{r} \sigma I_{d r}+\frac{M}{L_{s} \omega_{s}} V_{q s}\right)+\omega_{s} \Phi_{q s} \\
-R_{s} \cdot a \Phi_{q s}+R_{s} \cdot c\left(L_{r} \sigma I_{q r}+\frac{M}{L_{s} \omega_{s}} V_{d s}\right)-\omega_{s} \Phi_{d s} \\
\frac{1}{\sigma L_{r}}\left(-R_{r} \cdot b\left(L_{r} \sigma I_{d r}+\frac{M}{L_{s} \omega_{s}} V_{q s}\right)+R_{r} \cdot c \Phi_{d s}+\omega_{r}\left(L_{r} \sigma I_{q r}+\frac{M}{L_{s} \omega_{s}} V_{d s}\right)\right) \\
\frac{1}{\sigma L_{r}}\left(-R_{r} \cdot b\left(L_{r} \sigma I_{q r}+\frac{M}{L_{s} \omega_{s}} V_{d s}\right)+R_{r} \cdot c \Phi_{d s}-\omega_{r}\left(L_{r} \sigma I_{d r}+\frac{M}{L_{s} \omega_{s}} V_{q s}\right)\right)
\end{array}\right]} \\
=f(x, t) \cdot
\end{gathered}
$$

Sliding surfaces in the Park marker are defined to control the rotor currents. They are given by the following equations: 


$$
\left\{\begin{array}{l}
S_{d}=\lambda\left(I_{d r r e f}-I_{d r}\right) \\
S_{q}=\lambda\left(I_{\text {qref }}-I_{q r}\right),
\end{array}\right.
$$

where $V_{d r}$ and $V_{q r}$ are the two control vectors, to force the system path to converge to surfaces $S_{d q}=0$.

The control vector $U_{\text {dqeq }}$ is obtained by imposing $S_{d q}=0$

$$
f(x, t)+g(x, t) U_{d q}=0 ;
$$

$U_{\text {eqdq }}=\left[\begin{array}{l}-\left(-R_{r} \cdot b\left(L_{r} \sigma I_{d r}+\frac{M}{L_{s} \omega_{s}} V_{q s}\right)+R_{r} \cdot c \Phi_{d s}+\omega_{r}\left(L_{r} \sigma I_{q r}+\frac{M}{L_{s} \omega_{s}} V_{d s}\right)\right) \\ -\left(R_{r} \cdot b\left(L_{r} \sigma I_{q r}+\frac{M}{L_{s} \omega_{s}} V_{d s}\right)+R_{r} \cdot c \Phi_{q s}-\omega_{r}\left(L_{r} \sigma I_{d r}+\frac{M}{L_{s} \omega_{s}} V_{q s}\right)\right)\end{array}\right]$.

To have good performance, good dynamics and good switching around surfaces the control vector is imposed as follows:

$$
U_{d q}=U_{d q e q}+\operatorname{Ksign}\left(S_{d q}\right) .
$$

Simulation results. The figures below (Fig. 6) represent the different curves by the simulation of the DFIG with sliding mode controllers.
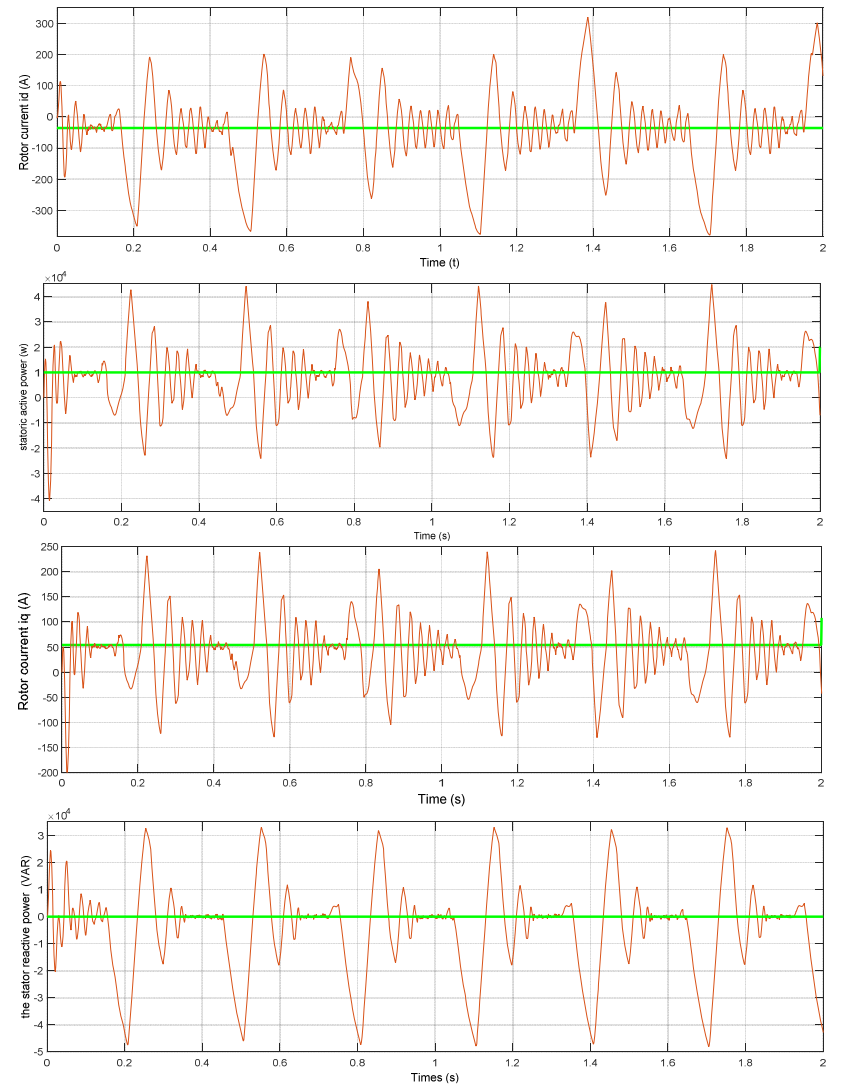

Fig. 6. Simulation results of the system GADA and voltage inverter

Its characteristics have allowed us to cite the performance of regulators in sliding mode, such as:

- good continues stator currents compared to references;

- perfect decoupling between the two components of the stator current.

Therefore, the control of the active power of the stator is by the direct component of the current, while the reactive power of the stator of the quadratic component of the stator current.

In order to test the robustness of this control structure by sliding mode, we studied the influence of parametric variations on the performance of the adjustment. We consider variations on all parameters that can undergo changes (stator and rotor resistors, stator, rotor and mutual inductors, and moment of inertia).

The results of the test of robustness to variations of the reference power simulation obtained show that decoupling is ensured at all times of the active and reactive powers, despite the presence of slight oscillations which are due to the Chattering phenomenon (Fig. 7).
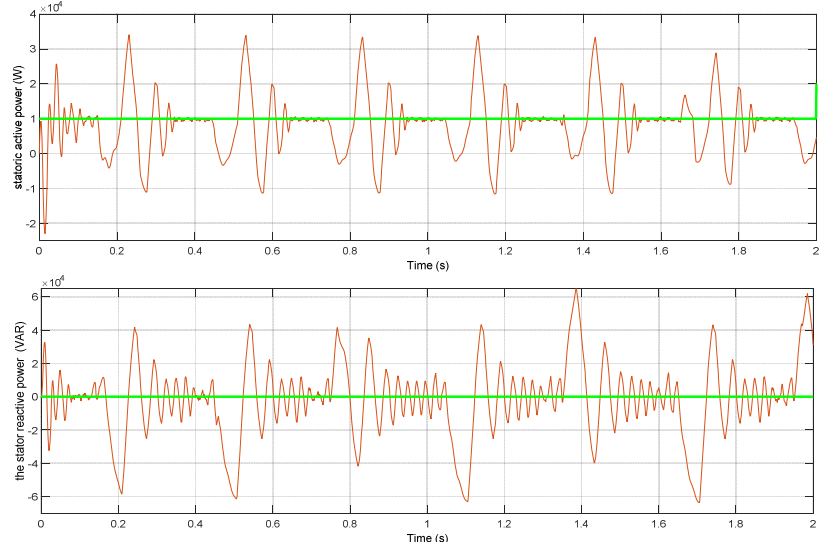

Fig. 7 Results of the system with the function sign

The results obtained in Fig. 8, 9 show that decoupling is ensured at all times of the active and reactive powers, despite the presence of slight oscillations that are due to the Chattering phenomenon.
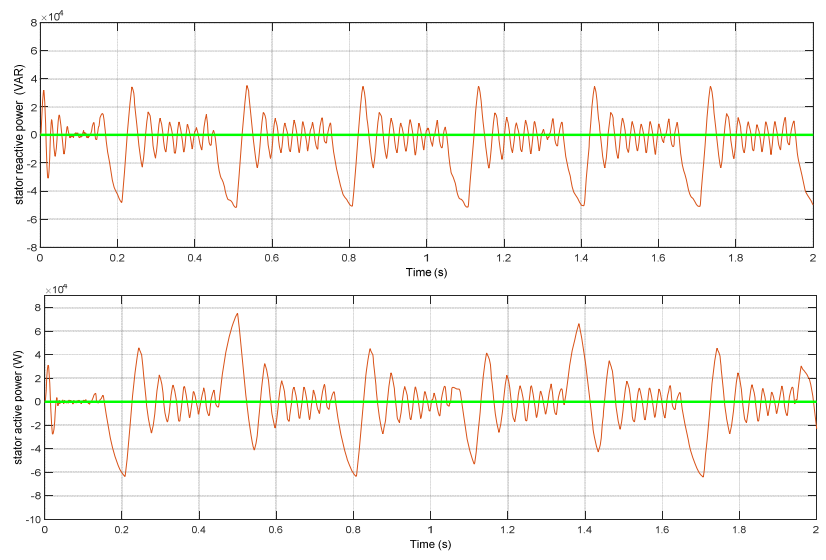

Fig. 8. Robustness test for a variation of $R_{s}$
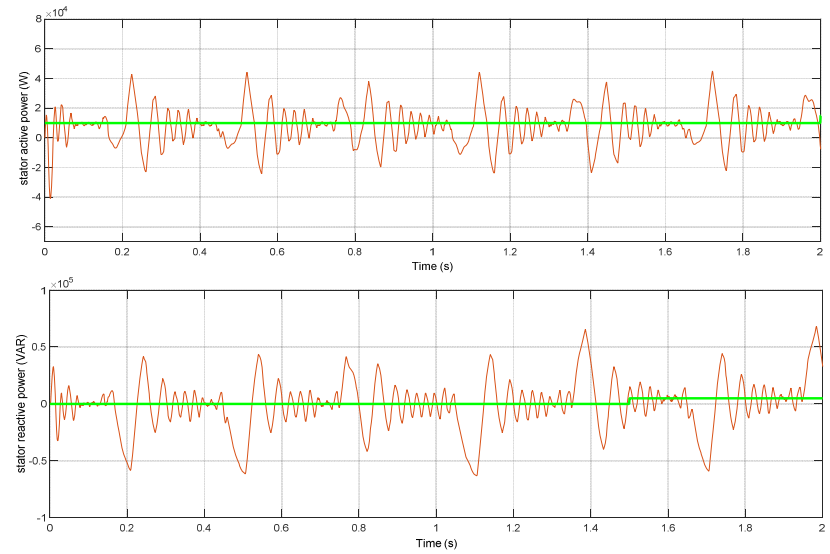

Fig. 9. Robustness test for a variation of $R_{r}$

Conclusion. In this paper, a complete system for electrical energy production has been done via wind 
turbine by use of the doubly fed induction generator (DFIG). The studied system has been formed of a DFIG with stator and rotor, which in that stator has connected to the grid directly, machine converter and grid converter. With the consideration of turbine variable velocity state and design controller for DFIG in form of using of the sliding mode.

Firstly, we have introduced the simplicity of the control variable structure by sliding mode non-linear switching surface. Then, we are interested more closely in the application of this type of control on the asynchronous machine with double feeding. The setting of the active and reactive powers by the sliding mode brings a remarkable improvement and good system performance with DFIG.

The results of the simulations obtained are evaluated and carried out using the Matlab / Simulink software and show the performance and the effectiveness of the proposed control.

\section{REFERENCES}

1. Johnstone C.M., Nielsen K., Lewis T., Sarmento A., Lemonis G. EC FPVI co-ordinated action on ocean energy: A European platform ford sharing technical information and research outcomes in wave and tidal energy systems. Renewable Energy, 2006, vol.31, no.2, pp. 191-196. doi: 10.1016/j.renene.2005.08.015.

2. Ben Elghali S.E. et al. Les systèmes de génération d'énergie électriques à partir des courants de mare. Revue 3EI, 2008, no. 52, pp. 73-85.

3. Benbouzid M.E.H. et al. Marine tidal current electric power generation technology: State of the art and current status. Proceedings of IEEE IEMDC'07, May 2007, Antalya (Turkey), vol.2, pp. 1407-1412.

4. Myers L., Bahaj A.S. Simulated electrical power potential harnessed by marine current turbine arrays in the Alderney Race. Renewable Energy, 2005, vol.30, no.11, pp. 1713-1731. doi: 10.1016/j.renene.2005.02.008.

5. Couch S.J., Bryden I. Tidal current energy extraction: Hydrodynamic resource characteristics. Proceedings of the Institution of Mechanical Engineers, Part M: Journal of Engineering for the Maritime Environment, 2006, vol.220, no.4, pp. 185-194. doi: 10.1243/14750902jeme50.

6. Taraft S., Rekioua D., Aouzellag D., Bacha S. A proposed strategy for power optimization of a wind energy conversion system connected to the grid. Energy Conversion and Management, 2015, vol.101, pp. 489-502. doi: 10.1016/j.enconman.2015.05.047.

7. Mobayen S., Tchier F. Robust global second-order sliding mode control with adaptive parameter-tuning law for perturbed dynamical systems. Transactions of the Institute of Measurement and Control, June 2017, p. 014233121770883. doi: $10.1177 / 0142331217708832$.

8. Ansarifar G.R., Rafiei, M. Second-order sliding-mode control for a pressurized water nuclear reactor considering the xenon concentration feedback. Nuclear Engineering and Technology, 2015, vol.47, no.1, pp. 94-101. doi: 10.1016/j.net.2014.11.003.

9. Bartolini G., Levant A., Pisano A., Usai E. Adaptive secondorder sliding mode control with uncertainty compensation. International Journal of Control, 2016, vol.89, no.9, pp. 17471758. doi: 10.1080/00207179.2016.1142616.

10. Benbouzid M., Beltran B., Mangel H., Mamoune A. A highorder sliding mode observer for sensorless control of DFIGbased wind turbines. IECON 2012 - 38th Annual Conference on
IEEE Industrial Electronics Society, Oct. 2012, Montreal, Canada. pp. 4288-4292. doi: 10.1109/iecon.2012.6389200.

11. Evangelista C.A., Valenciaga F., Puleston P. Multivariable 2-sliding mode control for a wind energy system based on a double fed induction generator. International Journal of Hydrogen Energy, 2012, vol.37, no.13, pp. 10070-10075. doi: 10.1016/j.ijhydene.2011.12.080.

12. Sun H., Han Y., Zhang L. Maximum Wind Power Tracking of Doubly Fed Wind Turbine System Based on Adaptive Gain Second-Order Sliding Mode. Journal of Control Science and Engineering, vol. 2018, pp. 1-11. doi: 10.1155/2018/5342971.

13. Kassem A.M., Hasaneen K.M., Yousef A.M. Dynamic modeling and robust power control of DFIG driven by wind turbine at infinite grid. International Journal of Electrical Power \& Energy Systems, 2013, vol.44, no.1, pp. 375-382. doi: 10.1016/j.ijepes.2011.06.038.

14. Belmokhtar K., Doumbia M.L., Agbossou K. Novel fuzzy logic based sensorless maximum power point tracking strategy for wind turbine systems driven DFIG (doubly-fed induction generator). Energy, 2014, vol.76, pp. 679-693. doi: 10.1016/j.energy.2014.08.066.

15. Weng Y.-T., Hsu Y.-Y. Sliding mode regulator for maximum power tracking and copper loss minimisation of a doubly fed induction generator. IET Renewable Power Generation, 2015, vol.9, no.4, pp. 297-305. doi: 10.1049/ietrpg.2014.0125.

16. Abdeddaim S., Betka A. Optimal tracking and robust power control of the DFIG wind turbine. International Journal of Electrical Power \& Energy Systems, 2013, vol.49, no.1, pp. 234-242. doi: 10.1016/j.ijepes.2012.12.014.

17. Myers L., Bahaj A.S. Power output performance characteristics of a horizontal axis marine current turbine. Renewable Energy, 2006, vol.31, no.2, pp. 197-208. doi: 10.1016/j.renene.2005.08.022.

18. Bossanyi E. Wind Energy Handbook. New York: Wiley, 2000.

19. Bin Wang. On Discretization of Sliding Mode Control Systems. Theses doctorate, School of Electrical and Computer Engineering RMIT University Melbourne, Australia, 2008.

20. Harmouche M. Contribution to the theory of higher order sliding mode control and the control of underactuated mechanical systems. Theses Doctorate, Universite de technologie de Belfort-Montbeliard, France, 2017.

21. Laghrouche S., Chitour Y., Harmouche M., Ahmed F.S. Path Following for a Target Point Attached to a Unicycle Type Vehicle. Acta Applicandae Mathematicae, 2012, vol.121, no.1, pp. 29-43. doi: 10.1007/s10440-012-9672-8.

22. Harmouche M., Laghrouche S., Ahmed F.S., Bagdouri M.E. Second-order sliding mode controllers: an experimental comparative study on a mechatronic actuator. Proceedings of the Institution of Mechanical Engineers, Part I: Journal of Systems and Control Engineering, 2012, vol.226, no.9, pp. 1231-1248. doi: $10.1177 / 0959651812454061$.

23. Batten W.M.J., Bahaj A.S., Molland A.F., Chaplin J.R. Hydrodynamics of marine current turbines. Renewable Energy, 2006, vol.31, no.2, pp. 249-256. doi: 10.1016/j.renene.2005.08.020.

24. Harrouz A., ben Atialah A., Harrouz O. Modeling of small wind energy based of PMSG in south of Algeria. 2012 2nd International Symposium On Environment Friendly Energies And Applications, Jun. 2012, pp. 191-195. doi: 10.1109/efea.2012.6294042.

25. Bahaj A.S., Molland A.F., Chaplin J.R., Batten W.M.J. Power and thrust measurements of marine current turbines under various hydrodynamic flow conditions in a cavitation tunnel and a towing tank. Renewable Energy, 2007, vol.32, no.3, pp. 407-426. doi: 10.1016/j.renene.2006.01.012. 
26. Muller S., Deicke M., De Doncker R.W. Doubly fed induction generator systems. IEEE Industry Applications Magazine, 2002, vol.8, no.3, pp. 26-33. doi: 10.1109/2943.999610.

27. Park J.W., Lee K.W., Lee H.J. Wide speed operation of a doubly-fed induction generator for tidal current energy. 30th Annual Conference of IEEE Industrial Electronics Society, 2004. IECON 2004. Busan (South Korea). doi: 10.1109/iecon.2004.1431771.

28. Multon B., Robin G., Gergaud O., Ben Ahmed H. Le génie électrique dans le vent : Etat de l'art dans le domaine de la génération éolienne. congres Jeunes Chercheurs en Genie Electrique 2003, June 2003, Saint Nazaire, France. 10 p.

29. Carrasco J.M., Franquelo L.G., Bialasiewicz J.T., Galvan E., PortilloGuisado R.C., Prats M.A.M., Leon J.I., Moreno-Alfonso $\mathrm{N}$. Power-electronic systems for the grid integration of renewable energy sources: A survey. IEEE Transactions on Industrial Electronics, 2006, vol.53, no.4, pp. 1002-1016. doi: 10.1109/tie.2006.878356.

30. Tapia G., Tapia A., Ostolaza J.X. Proportional-integral regulator-based approach to wind farm reactive power management for secondary voltage control. IEEE Transactions on Energy Conversion, 2007, vol.22, no.2, pp. 488-498. doi: 10.1109/tec.2005.858058.

31. Tapia A., Tapia G., Ostolaza J.X., Saenz J.R. Modeling and control of a wind turbine driven doubly fed induction generator. IEEE Transactions on Energy Conversion, 2003, vol.18, no.2, pp. 194-204. doi: 10.1109/tec.2003.811727.

How to cite this article:

Glaoui H., Harrouz A. Sliding mode control of the DFIG used in wind energy system. Electrical engineering \& electromechanics, 2018, no.3, pp. 61-67. doi: 10.20998/2074-272X.2018.3.08.
32. Koutroulis E., Kalaitzakis K. Design of a maximum power tracking system for wind-energy-conversion applications. IEEE Transactions on Industrial Electronics, 2006, vol.53, no.2, pp. 486-494. doi: 10.1109/tie.2006.870658.

33. Xu L., Cartwright P. Direct active and reactive power control of DFIG for wind energy generation. IEEE Transactions on Energy Conversion, 2006, vol.21, no.3, pp. 750-758. doi: 10.1109/tec.2006.875472.

34. Glaoui H., Abdelkader H., Messaoudi I., Saab H. Modelling of Wind Energy on Isolated Area. International Journal of Power Electronics and Drive System (IJPEDS), 2014, vol.4. no.2, pp. 274-280. doi: 10.11591/ijpeds.v4i2.4859.

Received 06.03.2018

Hachemi Glaoui ${ }^{1}$, Ph.D.,

Abdelkader Harrouz ${ }^{2}$, Ph.D.,

${ }^{1}$ Department of Electrical Engineering,

Tahri Mohamed Bechar University,

Bechar, Algeria,

e-mail: glaouih@yahoo.fr

${ }^{2}$ Department of Hydrocarbon and Renewable Energy,

Ahmed Draia University,

Adrar, Algeria,

e-mail: harrouz@univ-adrar.dz 